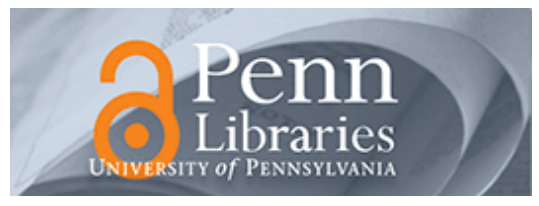

University of Pennsylvania

ScholarlyCommons

Marketing Papers

Wharton Faculty Research

November 2003

\title{
The Ombudsman: Reaping Benefits from Management Research: Lessons from the Forecasting Principles Project
}

\author{
J. Scott Armstrong \\ University of Pennsylvania, armstrong@wharton.upenn.edu \\ Ruth Pagell \\ Emory University
}

Follow this and additional works at: https://repository.upenn.edu/marketing_papers

\section{Recommended Citation}

Armstrong, J. S., \& Pagell, R. (2003). The Ombudsman: Reaping Benefits from Management Research: Lessons from the Forecasting Principles Project. Retrieved from https://repository.upenn.edu/ marketing_papers/102

Postprint version. Published in Interfaces, Volume 33, Issue 6, November 2003, pages 89-111.

Publisher URL: http://www.aaai.org/AITopics/html/interfaces.html

This paper is posted at ScholarlyCommons. https://repository.upenn.edu/marketing_papers/102

For more information, please contact repository@pobox.upenn.edu. 


\title{
The Ombudsman: Reaping Benefits from Management Research: Lessons from the Forecasting Principles Project
}

\begin{abstract}
It is often claimed that managers do not read serious research papers in journals. If true, this neglect would seem to pose a problem because journals are the dominant source of knowledge in management science. By examining results from the forecasting principles project, which was designed to summarize all useful knowledge in forecasting, we found that journals have provided 89 percent of the useful knowledge. However, journal papers relevant to practice are difficult to find because fewer than three percent of papers on forecasting contain useful findings. That turns out to be about one useful paper per month over the last half-century. Once found, the papers are difficult to interpret. Managers need low-cost, easily accessible sources that summarize advice (principles) from research; journals do not meet this need. To increase the rate of progress in developing and communicating principles, researchers, journal editors, textbook writers, software developers, web site designers, and practitioners should make some changes. Some examples: Researchers should directly study forecasting principles. Journal editors should actively solicit papers - invited submissions were about 20 times better than standard submissions at producing useful findings that were often cited, and does so at a lower cost. Web-site and software developers should provide practitioners with low-cost ways to use principles. Practitioners should apply the principles that are currently available.
\end{abstract}

\section{Keywords}

journals, meta-analysis, peer review, principles, software, websites

\section{Comments}

Postprint version. Published in Interfaces, Volume 33, Issue 6, November 2003, pages 89-111.

Publisher URL: http://www.aaai.org/AITopics/html/interfaces.html 


\title{
Reaping Benefits from Management Research: Lessons from the Forecasting Principles Project, with Reply to Commentators
}

\author{
J. Scott Armstrong, The Wharton School \\ Ruth Pagell, Emory University \\ Published in Interfaces, 33 (5), 2003, pp. 1-21
}

\begin{abstract}
It is often claimed that managers do not read serious research papers in journals. If true, this neglect would seem to pose a problem because journals are the dominant source of knowledge in management science. By examining results from the forecasting principles project, which was designed to summarize all useful knowledge in forecasting, we found that journals have provided 89 percent of the useful knowledge. However, journal papers relevant to practice are difficult to find because fewer than three percent of papers on forecasting contain useful findings. That turns out to be about one useful paper per month over the last half-century. Once found, the papers are difficult to interpret. Managers need low-cost, easily accessible sources that summarize advice (principles) from research; journals do not meet this need. To increase the rate of progress in developing and communicating principles, researchers, journal editors, textbook writers, software developers, web site designers, and practitioners should make some changes. Some examples: Researchers should directly study forecasting principles. Journal editors should actively solicit papers - invited submissions were about 20 times better than standard submissions at producing useful findings that were often cited, and does so at a lower cost. Web-site and software developers should provide practitioners with low-cost ways to use principles. Practitioners should apply the principles that are currently available.
\end{abstract}

Keywords: journals, meta-analysis, peer review, principles, software, websites. Acknowledgments: In addition to the commentators. Robert Fildes and Richard Franke provided useful suggestions. 


\section{What is Useful Knowledge for Forecasting?}

Consider the plight of practitioners who wish to improve their practice, say in forecasting. They seem to rely primarily on software, give some attention to books, courses, and consultants, and generally ignore journals. Should they read journals, as good physicians do, to learn about useful scientifically supported knowledge?

By useful knowledge, we mean knowledge that can help people improve their forecasting. To be useful, this knowledge must allow a forecaster to determine what actions to take in a given situation. We refer to such condition and action statements as forecasting principles, although they also might be called advice, rules, or guidelines. An example of a principle is, "When uncertainty is high, combine forecasts from two or more forecasting methods.” When a principle has empirical support, we refer to it as a grounded principle.

The forecasting principles project, begun in 1997, was designed to assess all useful knowledge in forecasting and to formulate the knowledge as principles. It led to a book, Principles of Forecasting, and a web site, forecastingprinciples.com. Scott Armstrong invited researchers to participate in writing a book that would describe principles and all relevant evidence in their areas of expertise. Forty experts responded to this invitation. In addition, 123 outside reviewers, primarily but not exclusively academics, helped to identify principles and evidence. Appeals for evidence were sent out on e-mail lists and on forecastingprinciples.com. Academics and practitioners visit this site. We encourage continuing open peer review on this site to identify errors and omissions in the principles.

For the purposes of this paper, the operational definition of useful knowledge is any direct evidence related to the principles contained in Principles of Forecasting (Armstrong 2001). The principles consist of the 139 in the summary chapter and many others described throughout the book.

In early 2001, we surveyed the authors of the 27 papers who provided the principles in the Principles of Forecasting. We asked them to indicate which references in their papers provided evidence on principles. They coded their references as "no evidence," "indirect evidence," "direct evidence," and "cannot remember or not sure.” We left the definition of "evidence" to them. Presumably, the evidence could include logical deduction from known facts, expert opinion, and empirical evidence. As it turned out, they seemed to rely most heavily on empirical evidence. The authors coded the references in their own papers, except for three papers 
(which Armstrong coded). This process resulted in 545 referenced items that provided direct evidence, some of which were referred to numerous times. (They are listed on the researchers page at forecastingprinciples.com.)

\section{Where does Evidence on Principles Come From?}

Papers in journals are the primary source of direct evidence on forecasting, with 89 percent of the 545 items (Table 1). An additional three percent were working papers, and two percent were proceedings papers. Books provided six percent of the items although this percentage understates their impact because some books were cited many times. Remarkably, commercial sources provided little evidence relevant to forecasting principles. Only one citation was to a trade journal, and practitioners were involved as authors on only seven percent of the journal papers.

\section{Table 1: Direct evidence on forecasting principles is provided mostly by journals $(n=545)$}

Academic Journals

Percent

Working papers

Proceedings

3

Books (including chapters)

The seven percent participation of practitioners seems low. For example, Hubbard and Lindsay (2002) estimated that about 14 percent of the papers published in major academic journals in marketing had practitioners as authors or coauthors. They also found that the participation of practitioners had dropped steadily from 44 percent prior to 1960.

The evidence came from a wide variety of journals. Eight of the journals had 10 or more items, and over half provided only one item. From 1978 to 2000, only three journals averaged more than one paper per year: the International Journal of Forecasting at 4.9, the Journal of Forecasting at 1.9, and Organizational Behavior and Human Performance/Decision Process with 1.1. 


\section{Finding and Interpreting the Evidence on Principles}

Given the diversity of the sources, practitioners cannot feasibly track the literature relevant to their needs through journals, even with computer searches. Consider our experience in searching for papers on combining forecasts. An electronic search of the Social Science Citation Index (SSCI) using “combining” and "forecasts” from 1988 to 2000 produced 115 papers. But only nine of these (about eight percent) contained evidence on principles. Suggestions from key researchers and references in papers on combining led us to 57 relevant papers, among them the nine found in the computer searches. Thus, by using computer searches we found only 16 percent of the relevant papers. So even if a practitioner were to have access to the SSCI, computer searches would be neither efficient nor sufficient in identifying useful studies. Furthermore, once papers are identified, it is still an expensive process for practitioners to obtain them.

When papers are obtained, one must translate their author's findings into principles. This was the task faced by the authors of the Principles book, and it was difficult. Journal papers are typically written in an arcane, often incomprehensible fashion, and show little direct concern for principles. And, as is so often the case with studies in management science, many researchers failed to describe the conditions under which their findings hold. For example, in a study of 1,700 empirical papers published by six leading marketing journals from 1984 to 1999, Armstrong, Brodie and Parsons (2001) found that only 11 percent of the papers had hypotheses that included conditions.

In view of the uncertainties over interpretation, the principles for nine papers in Principles of Forecasting (those written by Armstrong) were sent to the authors whose works were cited. While these authors typically agreed with Armstrong's interpretation, they did not always do so. Their suggestions led to improvements in the principles and to the identification of additional evidence.

\section{Improving the Development of Principles on Forecasting}

The 545 papers with direct evidence represent about one paper per month over the latter half of the $20^{\text {th }}$ century, and they constituted a small percentage of the papers published on forecasting. For example, we searched for "forecasting" in titles, key words, or abstracts in the SSCI and located an average of 17 articles per month from 1986 to 2002. However, many 
papers relevant to forecasting do not have forecasting in the title, key words or abstracts. For example, only about 42 percent of the 545 papers with direct evidence had the word "forecast" (or a variant) in the title. Thus, if this ratio applied to other areas of forecasting, only about one in 40 (i.e., 17 divided by .42) papers on forecasting would contain useful findings.

This small percentage (2.5) of useful papers is especially disappointing when one considers that, on average, there are only about four papers for each of the 139 principles. Worse, the distribution of studies is unequal. Some principles have been studied extensively, while many have been ignored.

Much can be done to increase knowledge about forecasting principles. We discuss what can be done by researchers, journal editors, textbook writers, software developers, web site designers, and practitioners.

\section{Researchers}

To learn more about forecasting principles, researchers should undertake studies designed to provide evidence related to forecasting principles. If researchers depend on serendipity, as has been common in the past, progress over the next half century will be slow.

To aid researchers in selecting topics, a listing of research needs is provided on the Researchers' Page at forecastingprinciples.com. Research needs are high for 23 principles. Some examples are "Obtain information from similar (analogous) series or cases" and "Damp seasonal factors for uncertainty."

Researchers also should take responsibility for communicating their findings. For example, those who obtain useful findings should, in the article abstract, explain specifically what they found and how. That would help others doing meta-analyses to judge whether the paper provided useful information. Unfortunately, academic papers often omit such essential information. For example, Armstrong coded abstracts from two years (issues 16.2 to 18.2) of the International Journal of Forecasting and found that only 17 percent (12 of 69) contained findings and methods. The others provided only vague introductions about what was studied. Similarly, in coding of the last two years of the Journal of Forecasting, Armstrong showed that only nine percent (6 of 68) of the abstracts contained results. On average then, researchers referring to these journals would have easy access to only 13 percent of the findings.

We examined whether papers that provided useful findings receive more attention than those that did not. To do this, we analyzed papers published under the auspices of the 
International Institute of Forecasters. This included the Journal of Forecasting (JoF) from 1981 to 1985, and the International Journal of Forecasting (IJF) from 1985 to 1999. During that time, 109 papers in these journals contained useful findings. We then compared citation rates for these papers to rates for a sample of papers that were published in the same journal issues immediately before or after each "useful paper." (We used a probability scheme to select the papers before or after; if another paper from our useful list was selected, it was replaced and another selection was made.) As expected, papers with useful findings were cited more frequently. The mean citation rate for the 109 useful papers, 1.4 cites per year, was roughly twice that for the 84 benchmark papers at 0.7 .

\section{Journal Editors}

To take a simple first step, journal editors should refuse to publish papers until the authors wrote adequate abstracts explaining the findings and how they were obtained. Readers should be able to identify and understand the key findings without reading the entire paper.

In a review of empirical research, Armstrong (2003) showed that the traditional reviewing process screens out the more useful findings. As a result, the publication of important papers depends to a large extent on active intervention by editors. They should actively seek papers relevant to principles. The reviewer's role would change from deciding what to publish to improving papers that might be published.

Using the papers published under the auspices of the International Institute of Forecasters, we divided the papers into two groups: those submitted in the traditional manner; and those that received special treatment because they were invited, written by members of the editorial board, or accepted by editors who overruled reviewers recommending rejection. Armstrong coded the papers as having received special treatment or not. In most cases there was no uncertainty about the coding (e.g., editorial board members are listed in each issue). It is likely, however, that he was unable to identify all such papers and these errors would weaken the test.

Using his experience as an editor, Armstrong estimated that about $1 / 3$ of the published papers in the JoF and IJF received special treatment, while 2/3 came through the traditional channels. Given that over 90 percent of special treatment papers were published, while the about 20 percent of traditional papers are published, traditional papers came from a pool that was about nine times as large as the special-treatment pool. However, about half (53 of 109) of the useful 
papers published in the IJF and JoF came from the special treatment pool. Thus, although special treatment papers represented about one tenth of the papers submitted, they led to half of the useful papers published.

Among the useful papers, the special treatment papers were superior to those published through traditional channels. The 53 special-treatment papers were cited 2.0 times per year on average, versus 0.8 for the 56 traditional papers. Based on citation rates then, published specialtreatment papers were about 2.5 times better than published traditional papers.

A usefulness index can be developed on the two factors: whether the paper has useful findings and its average citation rate. On this index, invited papers were more than 20 times as effective as standard-submission papers (9 times 2.5) and obtained at lower cost to the journal.

Thus, by actively intervening in the submission and refereeing process, editors improved the publication rate for papers with important findings. Similar results have been found in other fields. Laband and Piette (1994), in a study of 28 economics journals, found higher citation rates for papers published by authors who had obvious connections to the editors. Similarly, in a study of 15 accounting journals, Smith and Laband (1995) found that citations for articles for which they could identify an author-editor connection were more than triple those for articles for which they saw no connection. In the five years after publication, 69 percent of authors with editorial connections were cited whereas 63 percent of those with no editorial connections were never cited. Campanario (1996) found a positive relationship between the percentage of papers by authors connected to a journal and the journal's citation impact factor.

Who should editors invite to publish papers? The obvious group is authors who have contributed to principles in the past. In addition, editors might provide open invitations for researchers willing to study specified topics. (For example, an invitation to submit work on forecasting principles has been posted on the Researchers page at forecastingprinciples.com.)

Why does special treatment work? Editors can invite papers from researchers who have been successful in the past, perhaps asking them to study designated topics. The authors are free to approach the problem in any way they like, and they can ask their peers to review their work.

The suggestion the editors actively intervene is not new. In a survey of editors of 28 education journals, Rodman and Mancini (1977) found that 89 percent of them published “inside track submissions.” The successful Journal of Economic Perspectives publishes only invited papers. Academics, however, commonly regard special treatment as unfair, as shown in the 
survey by Sherrell, Hair and Griffin (1989). But should fairness play a role in editorial decisions if the aim is scientific progress?

Journal editors might also intervene regarding the length of papers. We divided the 109 IJF and JoF papers with useful findings into five nearly equal-size groups. We compared the two quintiles with the shortest papers (a median of about 10 pages) to the two with the longest papers (with a median of about 20 pages). We then calculated the median annual citation rates for each group. We assumed that longer papers would be more important, and they did average 95 citations per article compared to .79 for the shorter papers. So doubling the pages increased citation rates by only 20 percent. While other explanations may exist for the small effect size, editors could try to increase overall citation rates for their journals by publishing more short papers (e.g., by asking authors to reduce the length of their papers). Such a strategy is especially

relevant now that journals can post the details needed for replications (e.g., data and methods) on a web site. Editors should be able to identify papers where length is justified, such as review papers and papers reporting a number of experiments.

\section{Textbook Writers}

Many books claim to contain principles when they do not. Armstrong and Schultz (1993) examined nine books claiming to have marketing principles; none contained useful marketing principles.

While books containing grounded principles are rare, some exist, and they have been favorably received. These include March and Simon's (1958) book on principles for the design of organizations and Maier's (1963) book on principles for conducting problem-solving meetings.

Unfortunately, forecasting textbooks do not contain many principles (Cox and Loomis 2001). To remedy this omission, authors can write books specifically to report principles. Indeed, the motivation behind the Principles of Forecasting book (Armstrong 2001) was to provide a comprehensive set of principles for forecasting.

\section{Web-site Designers}

Web-sites can provide users with low-cost access to principles. This implies the need for a central authoritative location that summarizes principles. This has been done in forecasting through the forecastingprinciples.com web site, supported by the Wharton School, Kluwer 
Academic Publishers, and the International Institute of Forecasters. This site, which is free, has won numerous awards since it was created in 1997.

Is there demand for information about principles? We examines examining traffic at the forecastingprinciples.com web site (Figure 1). Traffic from mid-1998 through 2002 grew rapidly. The site is first for the term "forecasting” on Google and other search engines.

Figure 1

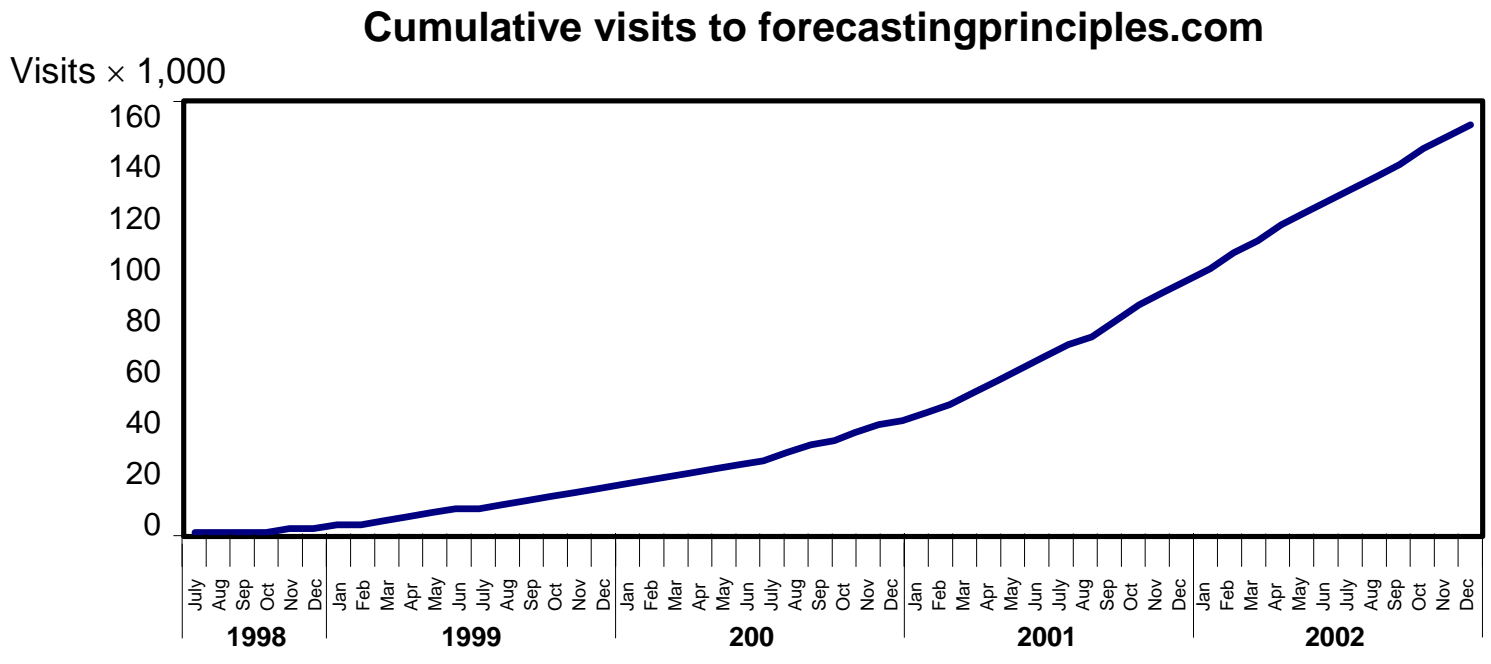

Reward systems in academic research are designed around inputs (published papers). Little concern is given as to whether the knowledge is useful or used. The Internet allows for measures of usefulness (continuing peer review along with commentary from practitioners), quality (continuing peer review and corrections), and use (e.g., site traffic and links). It is becoming easier to assess the positive impact of research. As a result, reward systems might slowly evolve to recognize researchers who provided useful evidence on the principles in a field.

Web-sites can provide easy accessibility to useful knowledge in a field. People who believe that principles are in need of revision or that useful principles have been overlooked can submit revisions or add new useful principles to the site. Continuing peer review can be published on the site. Errors and omissions can be used to update the principles. These benefits of web sites can help to ensure that the site and the related books and papers contain all useful knowledge in the field. 


\section{Software Developers}

The diffusion of principles will depend in part on how easy they are to implement. Software can play a major role. If the principles are incorporated into the software, they will be used.

Of the 139 major principles from the Principles of Forecasting handbook, only about 20 percent are currently used in software packages. No single program uses all 20 percent. is provided as The first item on the Software page at forecastingprinciples.com is a list of needs for forecasting software. For example, current packages do not help with the principle, "For prediction intervals, incorporate the uncertainty associated with the prediction of the explanatory variables,” and they provide little help with principles related to judgmental aspects of forecasting. We believe that software could help to apply most forecasting principles.

SAS and ForecastPro have stated that they will respond to client requests to add principles. This is a good policy. However, software developers are likely to have substantially more expertise than their clients. They should take the lead, and they should post notices when they update their software updates to implement new forecasting principles or improve the implementation of existing principles. Tashman and Hoover plan to monitor software developers’ notices about additions and revisions. Software companies should notify their customers when they add features that address principles.

In addition to commercial software, we urge people to post freeware. Freeware could be used to guide forecasters through judgmental forecasting procedures and to help them to select appropriate forecasting methods, to name two possibilities. For example, the forecastingprinciples.com site contains freeware that guides users through an audit of their forecasting procedures; it also contains Delphi software to help in the application of judgmental forecasting principles.

\section{Practitioners}

To the extent that practitioners rely on current practice, little progress will occur. People will continue to rely on unstructured judgment to make important forecasts. This will lead to the types of forecasts that lead to disasters, such as the dot.com crash.

Practitioners should ask developers to incorporate principles in their software, especially well grounded principles. Perhaps the easiest way for practitioners to identify these needs is to 
use the forecasting audit (at forecastingprinciples.com) for their forecasting problems. Of course, practitioners can use many of the principles without recourse to software.

Most important is that practitioners take advantage of the many principles developed for forecasting. This can be aided by guides on the forecastingprinciples.com website.

\section{Conclusions}

Researchers are slowly making useful findings even though research on important problems is little rewarded. Useful findings are difficult to publish, and once published, they are difficult to locate. In the area of forecasting, we found that only 13 percent of the abstracts in the two leading journals provided an adequate description of the papers. Once located, the papers may be difficult for practitioners to obtain. Those papers that are understandable often lack descriptions of the relevant conditions, thus making it difficult to see how they can be used. In view of these problems, it is understandable that practitioners do not rely on journals, even though that is where useful findings are reported. These problems are expected to be similar in other fields; as was shown in Armstrong (2003), for example, the problems are probably even more serious in the field of marketing.

In forecasting as in other areas of management science, we need to conduct research on principles, do meta-analyses to summarize knowledge as principles, and to make principles easily available through books, web sites, and software.

\section{Acknowledgements}

In addition to the commentators, Robert Fildes and Richard Franke provided useful suggestions.

\section{References}

Armstrong, J. S., ed., 2001, Principles of Forecasting. Boston, MA: Kluwer Academic Publishers.

Armstrong, J. S. 2003. "Discovery and communication of important marketing findings: Evidence and proposals,” Journal of Business Research, 56, 69-84 (commentaries and reply, pp. 85-92). Full text at jscottarmstrong.com. 
Armstrong, J. S. and R. L. Schultz, 1993, "Principles involving marketing policies: An empirical assessment,” Marketing Letters, 4 (3), 253-265. Full text at jscottarmstrong.com.

Armstrong, J. S., R. Brodie, A. Parsons 2001. "Hypotheses in marketing science: Literature review and publication audit,” Marketing Letters, 12 (2), 171-187. Full text at jscottarmstrong.com.

Campanario, J. M. (1996), "The competition for journal space among referees, editors, and other authors and its influence on journal's impact factors," Journal of the American Society for Information Science, 47 (3), 184-192.

Cox, J. E. \& D. G. Loomis (2001), "Diffusion of forecasting principles through books," in J. S. Armstrong (ed.), Principles of Forecasting. Boston, MA: Kluwer Academic Publishers.

Hubbard, R. and R. M. Lindsay (2002), "How the emphasis on 'original' empirical marketing research impedes knowledge development,” Marketing Theory, 2 (4), 381-388.

Laband, D. N. and M. J. Piette (1994), "Favoritism versus search for good papers: Empirical evidence regarding the behavior of journal editors,” Journal of Political Economy, 102, 194-203.

Maier, Norman R. F. (1963), Problem Solving Discussions and Conferences. New York: McGraw-Hill.

March, J. G. and H. S. Simon (1958), Organizations. New York: John Wiley and Sons.

Rodman, H. and J. A. Mancini (1977), "Errors, manuscripts, and equal treatment," Research in Higher Education, 7, 369-374.

Sherrell, D. L., J. F. Hair, Jr. and M. Griffin (1989), "Marketing academicians' perceptions of ethical behavior and publishing behavior," Journal of the Academy of Marketing Science, 17 (4), 315-324.

Smith, K. and D. N. Laband (1995), “The role of editor's professional connections in determining which papers get published: Evidence from accounting research journals," Accounting Perspectives, 1 (1), 21-30.

Tashman, L. J. \& J. Hoover (2001), “Diffusion of forecasting principles through software,” in J. S. Armstrong (ed.), Principles of Forecasting. Boston, MA: Kluwer Academic Publishers. 


\section{Reply to Comments: Incentives for Developing and Communicating Principles: A Reply}

\section{J. Scott Armstrong}

The commentators raised many. interesting ideas in response to Armstrong and Pagell (2003) from which one general theme emerges: The commentators claim that management science lacks the incentives to encourage efforts to develop and communicate grounded principles. As a result, academics often conduct their research as an intellectual exercise with little concern as to whether their findings might eventually be of any practical use.

The problem extends beyond management science. Smith (1991), an editor of the British Medical Journal, concluded from a review that only about 15 percent of medical interventions are supported by solid scientific evidence. He attributes this disconnect to an estimate that only about one percent of articles in medical journals are scientifically sound. Such results indicate problems with incentives in research.

\section{Disincentives}

The discovery of new and useful grounded principles carries the message that the currently accepted procedures may not provide the best solutions. Some forecasting procedures, such as Box-Jenkins (Armstrong 2001) and game theory (Green 2002), have been shown to be of little value. Other procedures, such as unit roots testing in econometric forecasting, have little empirical grounding to demonstrate theirr value (Allen and Fildes 2001). Some researchers may be annoyed by these conclusions, especially given that they are based on empirical evidence.

The history of science shows that many disincentives to scientific advances exist. Those who have made major advances have often been treated poorly. Kuhn (1962) claimed that when innovative findings conflict with important beliefs, resistance is likely to be strong and long lasting. For example, Richard Harrison's quest for an accurate timepiece, which was needed to 
determine longitude at sea, put him at odds with the scientific community of his day (Sobel 1995). Barber (1961) describes the fierce resistance met by famous scientists.

Present-day examples are easy to find. The Danish statistician Bjorn Lomborg (Lomborg 2001) was denounced by the Danish Committee on Scientific Dishonesty and by other groups largely because they did not agree with his findings that the environment is improving (lomborg.com). This argument had been made initially by the late Julian Simon (1981), who had also been denounced by many academics. Emotion usually runs high in such cases, even among those who have not read Lomborg's or Simon's publications.

The evidence for resistance to findings is more than anecdotal. Laboratory experiments summarized by Armstrong (1996) show that scientists commonly resist findings that challenge existing beliefs. Typically, they argue that the disconfirming findings are based. on poor methodology.

I cannot claim to be a disinterested party in this matter, having devoted considerable energy to discovering and communicating grounded principles. I believe my findings have had a positive impact, and I am currently the most frequently cited professor in the Wharton School's Marketing Department. However, the route I have taken has had. perils. Some people regard my findings as heresies (see findings at http://jscottarmstrong.com). Reviewers have nearly always rejected what I think to be my most important papers. Thanks to interventions by editors, however, most of my papers have eventually been published. I have described some of my adventures with reviewers (Armstrong 1996). I suspect my commitment to principles has affected. my internal promotional reviews at the Wharton School, especially in the late 1970s and the 1980s. Thanks to tenure, I still have a job. Fortunately, the administration and my colleagues have been supportive and done much to help me in recent years. Even so, I am 
currently paid about half of the usual pay for faculty at my rank at Wharton. Perhaps I will live long enough to gain parity.

\section{Incentives}

Not all grounded principles are controversial, of course. But what is the motivation to work on refining accepted principles? In many cases researchers go to great pains to show that their research is original, and journals look for “originality.” Findings that derive from prior work are not held in such high regard. At the extreme, reviewers have a low regard for replications, as noted by Hubbard and Vetter (1996).

Working on principles is time consuming. It is difficult to locate all the relevant studies and to translate them into useful findings. The job often requires reconciling conflicting results. It calls for an understanding of the conditions in the principles. Establishing principles is valuable work and it should be encouraged.

The commentators described a number of ways to improve incentives. Their suggestions have spurred. me to join. with others to take two related actions to encourage useful research on forecasting:

\section{Grants for Directed Research}

SAS has announced that it will provide two annual \$5,000 grants to the International Institute of Forecasters to support research directed at developing and testing forecasting principles. The funding process will focus on the research needs found on the Researchers page at forecastingprinciples.com, and the site will include details about how to apply.

\section{Invited Papers}

Recipients of an SAS grant will be invited to publish the resulting paper in the International Journal of Forecasting, The paper will also be subject to peer review In an effort 
to improve it. However, as is the case with the Journal of Economic Perspectives which relies almost solely on invited papers, authors are expected to seek peer review. I will also seek approval from the International Journal of Forecasting to extend additional invitations to researchers.

In addition to these efforts to encourage research, the following steps are planned to improve the communication of useful findings.

1. Informative Abstracts. The International Journal of Forecasting (IJF) has begun to ask authors to provide abstracts that describe their findings and procedures. The commentaries by Ord, Uncles, and Tashman offered. support for this proposal.

2. Reviews of Papers with Principles. To make new findings more accessible to others, the "Research on forecasting” section of the IJF is now encouraging reviewers to evaluate the papers in light of the forecasting principles summarized on forecastingprinciples.com.. In addition., authors of recently published papers are invited to describe how their work contributes to forecasting principles, with the descriptions to be posted at the forecastingprinciples.com site. The first posting, provided by Paul Goodwin, serves as a model.

3. Educational Materials. Books that contain information relevant to forecasting principles will be identified on the “Text and tradebooks” page at forecastingprinciples.com.

4. Special Interest Group Pages. Special Interest Group pages are being added at forecastingprinciples.com. The purpose is to provide the central source for those interested in forecasting in a particular area. Academics and practitioners are invited to host pages. Currently, Wil Gorr hosts a page on crime forecasting, and Kesten Green has a page on forecasting for conflict situations. 


\section{Future Prospects for Principles}

As Green mentions, more attention needs to be paid to assessing demand. With respect to the forecasting principles project, it would be useful to learn what principles have been used, and which of these have been useful. As a start, people who use the forecasting audit on. forecastingprindpies.com can provide their email addresses so that we can send them questionnaires regarding their use of principles.

The International |Institute of Forecasters is considering practitioner certification. This could be used to signify that people understand the forecasting principles and have some experience with them.

The increasing popularity of meta-analyses and the internet have reduced the cost of obtaining evidence on principles. In. addition, the Internet has provided people with the opportunity to learn about principles.

It is encouraging to see that similar projects have been successful. The Cochrane Collaboration (colchrane.org) was formed many years ago for "Preparing, maintaining and promoting the accessibility of systematic reviews of the effects of health-care interventions.” In 2000, the Campbell Collaboration (campbeflcoflaboration.org) was organized to find out "what helps, what harms, and based on what evidence” for problems in social, behavioral, and educational areas. In biology, the facultyof1000.corn classifies studies as "novel finding," “technical advance,” “interesting hypothesis,” “important confirmation,” or “controversial findings”; they then rate these papers so others can see which are recommended, must reads, or exceptional. Descriptions are also provided on why a paper is important. 
The technology is now in place for a revolution that would emphasize principles in various fields. While the primary barriers are those relating to disincentives and the lack of incentives, I am optimistic that these will change.

\section{Acknowledgments}

I received much help from others, in particular, Monica Adya, Robert Fildes, Paul Goodwin, Kesten Green, Raymond Hubbard, and Mark Uncles. This is not to imply that these reviewers agreed with everything here.

\section{References}

Allen, P Geoffrey, Robert Fildes (2001), “Econometric forecasting.” In J. S Armstrong (ed.), Principles of Forecasting. Kluwer, Boston, MA.

Armstrong, J- Scott (1996), “Management folklore and management science - On portfolio planning, escalation bias, and such,” Interface 26 (4), 28-42.

Armstrong, J. Scott (2001), “Extrapolation of time series and cross-sectional data,” In J. S Armstrong (ed.), Principles of Forecasting. Kluwer, Boston, MA.

J. Scott Armstrong and Ruth Pagell (2003), "Reaping benefits from management research: Lessons from the forecasting principles project,” Interfaces 33, xx.

Barber, Bernard (1961) "Resistance by scientists to scientific discovery,” Science, 134, 596-602.

Green, Kesten C. (2002), “A comparison of forecasting decisions in conflict situations: Game theory, role-playing, and unaided judgment,” International Journal of Forecasting, 18 (3), 321-344 (commentary, pp. 345-395). 
Hubbard, Raymond and Daniel E. Vetter (1996), “An empirical comparison of published replication research in accounting, economics, finance, management and marketing,” Journal of Business Research, 35 (2), 153-164.

Kuhn, Thomas S. (1962), The Structure of Scientific Revolutions. University of Chicago Press, Chicago, IL.

Lomborg, Bjorn (2001), The Skeptical Environmentalist: Measuring the Real State of the World. Cambridge University Press, New York.

Simon, Julian L. (1981), The Ultimate Resource. Princeton University Press, Princeton, NJ.

Smith, Richard (1991), "Where is the wisdom: The poverty of medical evidence,” British Medical Journal, 303 (6806), 798-799.

Sobel, Dava (1995), Longitude. Walker Publishing, New York. 